\title{
The Global Value Chains Effects of East Asia on the United States and the Sino-US Trade Transfer Imbalance
}

\author{
Lin Kong \\ School of Management, Capital Normal University, Beijing, China (lin15aa@163.com)
}

\begin{abstract}
As East Asia is covered by the global value chains rapidly, the increase of the US trade deficit with China and the decrease of the US trade deficit with East Asia occur simultaneously. Therefore, this paper analyzes the present Sino-US trade imbalance from this perspective. It explains the characteristics of the global value chains established by the US multinationals in East Asia, reveals the reasons of the rapid development of trade based on the global value chains in East Asia, calculates and analyzes the trade combination degree of the global value chains among East Asia, China and the US, in order to reflect the trade pattern and trade flows that China imports intermediate goods from East Asia, and exports final goods to developed countries after assembly more clearly, and explain the Sino-US trade transfer imbalance formed by the vertical transfer of the global value chains.
\end{abstract}

Keywords - global value chains, the Sino-US trade, transfer imbalance, East Asia, trade flows

\section{东亚对美国的全球价值链效应与中美贸易转移性失衡}

\author{
孔琳 \\ 首都师范大学管理学院, 北京, 中国
}

摘 要 随着全球价值链对东亚地区的迅速覆盖, 美国对中国贸易逆差的升高与对东亚贸易逆差的降低同步出现。因此, 本文基 于这一视角来分析现阶段的中美贸易不平衡问题, 阐述了美国在东亚形成的价值链特征, 揭示了东亚基于全球价值链贸易迅速发展的 原因, 计算并分析了东亚、中国和美国的价值链贸易结合程度, 以便更清晰地体现中国从东亚进口中间产品, 装配后再出口到发达国 家的贸易模式和贸易流向, 并解释由此带来的由于价值链的纵向转移而形成的中美贸易转移性失衡。

关键词 全球价值链, 中美贸易, 转移性失衡, 东亚, 贸易流向

\section{1. 引言}

中美双边贸易量从 20 世纪 80 年代早期开始就持续增 长, 特别是随着 90 年代中期以来中国经济的飞速发展以及 中国加入 WTO 以后, 中美双边贸易的增长更是突飞猛进, 中国对美国的出口也以加速增长的态势呈现在我们面前。 这样, 从绝对数额上来看, 美中贸易逆差非常显著, 但如 果从相对数额上来看, 根据联合国 Comtrade 数据库的相关 数据整理计算可得, 在美国的全球贸易逆差中, 美中贸易 逆差所占的比重从 1992 年的 $18.8 \%$ 增长到了 2013 年的 45. $0 \%$, 共增长了 26 个百分点, 而同期美国对东亚其他国 家 (地区) 的贸易逆差所占的比重却从 $53.8 \%$ 骤降到了

北京高校青年英才计划支持, 《中美贸易非均衡问题研究——基于 价值链贸易分析的最新进展》的阶段性成果之一。
8. $4 \%$, 总共下跌了 45 个百分点。即便我们把中国包括在东 亚地区内, 同期美国对东亚的贸易逆差在其全球贸易逆差 中的比重也在下降, 从 1992 年的 $72.6 \%$ 降到了 2013 年的 $53.4 \%$ 。究其原因, 主要是这二十年来, 随着东亚各先进经 济体产业的升级, 这些国家逐步将其价值链下游的低技术、 劳动密集型加工装配环节转移到中国, 组装成最终产品后 再对美出口, 这样他们就把自己对美国的贸易顺差通过加 工装配环节转移到了中国。因此, 本文拟从这一角度来分 析现阶段的中美贸易不平衡问题。

\section{2. 美国跨国公司在东亚形成的价值链体系}

随着技术的飞速发展进步以及现代金融体系和物流体 系的迅速建立, 消费需求呈现多样性变化, 企业能力也日 趋差异化。在这一背景下, 美国跨国公司改变了其在 20 世 
纪末形成的将采购、研发、制造、营销等价值链环节集中 于一个企业之中的生产组织形式, 形成了模块化的产业组 织模式, 并开始在全球寻找合适的供应商。由于美国跨国 公司具有对外投资的历史依赖和地理依赖, 因此, 就逐渐 形成了以中国为加工基地, 以东亚为供应中心的亚太分工 协作体系。这样, 美国跨国公司就将其生产环节中的原材 料筹供、阶段性生产和加工装配等环节外包出去, 将资源 全部集中于价值链上游的架构、标准以及研发、营销和品 牌等附加值高的环节上。

在东亚, 美国的跨国公司往往采用外包、合同制造以 及战略联盟等方式采购中间投入品和最终产品, 然后通过 自己的销售网络进行销售。这样，一大批合同制造商就在 亚洲迅速出现并发展起来。同时, 美国跨国公司也向东亚 企业提供生产中间产品所必需的规格和技术, 形成了与东 亚合同制造商之间的价值链上的互补关系。

此外, 美国跨国公司为了降低成本, 及时衔接, 还越 来越倾向于把某些流程外包出去。在这一背景下, 台湾、 新加坡、韩国和其他国家 (地区) 的本土企业就迅速发展 起来, 他们在遵循跨国公司要求的同时还具有比较大的生 产组织自主权, 而且可以建立并发展自己的生产网络。这 些区域生产网络的建立又进一步巩固了东亚作为美国中间 投入品生产基地的地位。

美国在东亚的价值链分工体系中, 美国跨国公司与东 亚企业之间主要是基于更为灵活的合同关系而不是股权关 系。价值链的主导企业可以选择不同的中间品提供商, 中 间品提供商也可以为多个跨国公司提供生产所需的零部 件。在美国在东亚所形成的价值链中, 东亚成熟的零部件 生产能力和较低的生产成本都被纳入到美国跨国公司主导 的生产和贸易网络中, 大大缩短了研发和生产时间, 提高 了专业化程度和市场竞争力。

\section{3. 基于全球价值链的贸易模式在东亚迅速发展的原 因}

在美国跨国公司在东亚构筑其全球生产和贸易网络的 同时, 基于全球价值链的贸易模式在东亚也迅速发展起来, 究其原因, 主要有以下几点:

首先是市场厚度优势。

东亚区域内一些国家经济的持续发展为全球价值链贸 易的发展提供了市场厚度等很好的微观运行条件, 这对跨 国公司外包选址将产生显著的正向影响(Grossman and Helpman, 2005)。

其次是制造业工资优势与区域内工资落差。

尽管基于全球价值链的贸易在东亚增长迅速, 但中国
和其他一些出口导向型国家 (马来西亚、越南、泰国、菲 律宾等）的制造业工资仍然低于欧洲和北美自由贸易区的 发展中国家。此外, 东亚各国 (地区) 之间巨大的工资落 差也为全球价值链贸易在东亚区域内的迅速扩展提供了基 础, 大大提高了跨境零部件贸易额。

再次是外包的深入发展与集聚优势。

外包的发展历程对东亚在基于全球价值链贸易上的迅 速发展也具有一定的作用。跨国公司选择的外包地点首先 是新加坡, 然后是马来西亚, 再到其他国家, 这体现了跨 国公司在一个国家或地区的投资时间越长, 对其所在地区 的投资传导性就越大, 也就会越深入、广泛地嵌入到东道 国所在地区。而且, 作为外资代工的先入地区，东亚的一 些国家和地区（特别是新加坡、韩国、中国台湾、马来西 亚等）对跨国公司来说具有很大的地理集聚优势。跨国公 司在进行新的生产基地选址时会在很大程度上考虑选定国 家及其邻国现有的市场主体状况。随着外包在东亚长期、 较为成熟地发展, 跨国公司 (尤其是美国跨国公司) 建在 东亚一些外包发展成熟的国家和地区（新加坡、中国台湾 等) 的分支机构所从事的环节也开始沿着全球价值链攀升。 这些都促进了东亚基于全球价值链贸易的迅速发展。

最后是服务链接成本优势。

优惠的贸易和投资政策、装备优良的港口、先进的通 讯设施以及要素的相对优势等都降低了全球价值链中服务 链接的成本, 推动了基于全球价值链的贸易在东亚的发展。

\section{4. 东亚一中国-美国价值链贸易的结合程度}

因为本文探讨的是东亚、中国、美国三地之间的价值 链贸易结合程度, 因此可依据Urata（2006）的三角贸易强 度指数来计算和分析。

令:

东亚-中国-美国价值链贸易额

$=$ 中国从东亚的中间产品进口额+中国对美国的最终产 品出口额

东亚-中国-美国价值链贸易比重

=东亚-中国-美国价值链贸易额/中国对外贸易总额 通过联合国Comtrade数据库SITC的相关数据计算可

知, 1992年到2013年东亚-中国-美国的价值链贸易发展迅 速。具体计算结果如表1所示。

从表1中的计算结果可知, 中国对外贸易总额的年均增 长率为 $16.6 \%$, 东亚-中国-美国的价值链贸易总额也以超过 $15 \%$ 的年均增长率迅速攀升。其中, 中国从东亚的中间产品 进口额年均增长 $13.1 \%$, 中国对美国最终产品出口额年均增 长 $20.5 \%$ 。这一相对量上的差异使得东亚-中国-美国价值链 
贸易比重随时间推移出现了小幅下降。但即便在这一价值 链贸易比重有所下降后, 东亚-中国-美国价值链贸易模式
在中国对外贸易总额中所占的份额仍然维持在 $20 \%$ 以上, 可 见其对中国对外贸易的作用举足轻重。

表1 东亚-中国-美国价值链贸易额及其比重

\begin{tabular}{|l|c|c|c|c|}
\hline \multicolumn{1}{|c|}{ 年份 } & 1992 & 1999 & 2006 & 2013 \\
\hline 中国从东亚的中间产品进口额 & 371.34 亿美元 & 801.45 亿美元 & 2084.12 亿美元 & 4928.43 亿美元 \\
\hline 中国对美国的最终产品出口额 & 69.86 亿美元 & 338.05 亿美元 & 1783.29 亿美元 & 3507.42 亿美元 \\
\hline 东亚-中国-美国价值链贸易额 & 441.20 亿美元 & 1139.50 亿美元 & 3867.41 亿美元 & 8435.85 亿美元 \\
\hline 中国对外贸易总额 & 1655.25 亿美元 & 3606.30 亿美元 & 17603.96 亿美元 & 41590.00 亿美元 \\
\hline 东亚-中国-美国价值链贸易比重 & $26.65 \%$ & $31.60 \%$ & $21.97 \%$ & $20.28 \%$ \\
\hline
\end{tabular}

资料来源：计算、整理自联合国Comtrade数据库

为了更清晰的显示东亚-中国-美国价值链贸易的结合 程度, 我们继续借用三角贸易强度指数来计算和说明。

令东亚-中国-美国价值链贸易的结合程度指数为 $\varphi$,

$$
\varphi=\frac{\mathrm{M}_{\mathrm{EA}}^{\text {China }}}{\mathrm{M}_{\text {World }}^{\text {China }}} \times \frac{\mathrm{F}_{\text {China }}^{\mathrm{USA}}}{\mathrm{F}_{\text {China }}^{\text {World }}}
$$

上式中:

$\mathrm{M}_{\mathrm{EA}}^{\mathrm{China}}$ 表示中国从东亚的中间产品进口额。

$\mathrm{M}_{\text {World }}^{\text {China }}$ 表中国中间产品的进口总额。

$\mathrm{F}_{\text {China }}^{\mathrm{USA}}$ 表示中国对美国的最终产品出口额。

$\mathrm{F}_{\text {China }}^{\text {World }}$ 表示中国最终产品的出口总额。
计算结果如表 2 所示。由表 2 的结算结果可知, 1999 年到 2013 年东亚-中国-美国的价值链贸易结合程度一直 维持在 $10 \%$ 以上的高位, 由于三角贸易强度的临界衡量指 标为 $10 \%$, 因此这一数据表明东亚-中国-美国的价值链贸 易结合程度较高, 价值链贸易形态明显。但如果我们纵观 这 20 年来东亚-中国-美国的价值链贸易结合程度指数的 变化, 就可以发现这一指数在 2013 年比 1999 年和 2006 年 略有下降。实际上这是由于我国从东亚进口的中间产品的 比重略有下降（从1999 年的 70. 37\%, 下降到 2013 年的 $58.12 \%$ ), 而同期我国对美国最终产品出口比重的变化却相 对稳定（一直围绕 20\%小幅变化）造成的。这也说明虽然 我国中间产品进口的来源地略有分散化, 但出口偏向不变, 不利于中美贸易的平衡发展。

表 2 东亚-中国-美国的价值链贸易结合程度

\begin{tabular}{|l|c|c|c|c|}
\hline \multicolumn{1}{|c|}{ 年份 } & 1992 & 1999 & 2006 & 2013 \\
\hline 中国从东亚的中间产品进口额 & 371.34 亿美元 & 801.45 亿美元 & 2084.12 亿美元 & 4928.43 亿美元 \\
\hline 中国中间产品的进口总额 & 464.41 亿美元 & 1138.90 亿美元 & 3395.99 亿美元 & 8479.75 亿美元 \\
\hline 中间产品比重 & $79.96 \%$ & $70.37 \%$ & $61.37 \%$ & $58.12 \%$ \\
\hline 中国对美国的最终产品出口额 & 69.86 亿美元 & 338.05 亿美元 & 1783.29 亿美元 & 3507.42 亿美元 \\
\hline 中国最终产品的出口总额 & 556.27 亿美元 & 1415.48 亿美元 & 7956.41 亿美元 & 18180.22 亿美元 \\
\hline 最终产品比重 & $12.56 \%$ & $23.88 \%$ & $22.41 \%$ & $19.29 \%$ \\
\hline 东亚-中国-美国的价值链贸易结合程度 & $10.04 \%$ & $16.81 \%$ & $13.76 \%$ & $11.21 \%$ \\
\hline
\end{tabular}

资料来源: 计算、整理自联合国Comtrade数据库 


\section{5. 结语}

本文分析了美国在东亚形成的全球价值链的形式和特 征, 并通过统计数据说明了美国对东亚贸易逆差的降低与 对中国贸易逆差的升高同步出现, 显示了全球价值链对东 亚地区的迅速覆盖, 以及东亚区域内供应采购网络的形成, 而且反映了在贸易的地理流向上, 中国既存在对东亚区域 内零部件进口的依赖, 又存在明显的制成品出口的区域外 偏向（欧美偏向）。这一进出口贸易流向体现了中国从东亚 进口中间产品, 装配后再出口到发达国家的贸易模式, 也 就是说, 实行外向型经济发展战略的东亚各经济体为中美 贸易提供了间接的全球价值链上生产链节的联系，形成了 处于生产过程不同阶段的零部件的多重跨境贸易, 这也是 基于全球价值链生产和贸易的一个显著表现。那么, 由此 带来的中美贸易失衡也就具有了由于价值链的纵向转移而 形成的转移性失衡这一特征。

\section{参考文献(References)}

[1] N. Aminian, K. Fung and F. Ng, "A comparative analysis of trade and economic integration in East Asia and Latin America,"
Economic Change and Restructuring, vol.42, no.1, pp. 105-137, 2009.

[2] S. W. Arndt, "Production Networks and the Open Macroeconomy," The Singapore Economic Review, vol.53, no.3, pp. 509-521, 2008.

[3] C. Filippini and V. Molini, "The Determinants of East Asia Trade Flows: A Gravity Equation Approach," Journal of Asian Economies, vol.14, no.5, pp. 695-711, 2003.

[4] G. Gereffi, J. Humphrey and T. Sturgeon, "The Governance of Global Value Chains," Review of International Political Econo$m y$, vol.12, no.1, pp.78-104, 2005.

[5] G. M. Grossman and E. Helpman, "Outsourcing in a Global Economy," Review of Economic Studies, vol.72, no.1, pp.135-159, 2005.

[6] E. Helpman, "Trade, FDI, and the Organization of Firms," Journal of Economic Literature, vol.44, no.3, pp. 589-630, 2006.

[7] J. Jongwanich, "Determinants of Export Performance in East and Southeast Asia," World Economy, vol.33, no.1, pp. 20-41, 2010.

[8] S. Rangan and R. Z. Lawrence, A Prism on Globalization. Washington, DC: Brookings Institution Press, 1999.

[9] L. E. Robert and S. Fredrik, "South-South FDI and Development in East Asia," Asian Development Review, vol.28, no.2, pp. 11-31, 2011. 